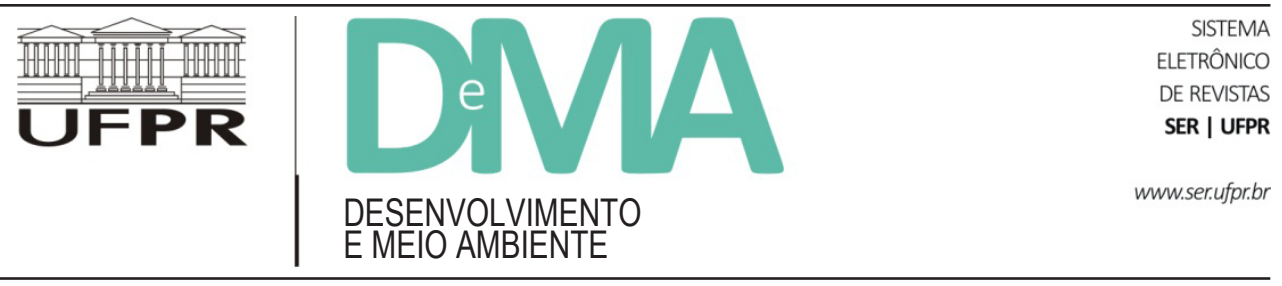

\title{
Resenha do livro "América Latina: sociedade e meio ambiente. Teorias, retóricas e conflitos em desenvolvimento"
}

\section{Book Review "América Latina: Sociedade e Meio Ambiente. Teorias, Retóricas e Conflitos em Desenvolvimento"}

FLORIANI, Dimas; HEVIA, Antonio Elizalde (Orgs.). América Latina: sociedade e meio ambiente. Teorias, retóricas e conflitos em desenvolvimento. Curitiba: Editora da UFPR, 2016. 348 p. ISBN: 9788584800278

\author{
Fernando Marcelo DE LA CUADRA ${ }^{1 *}$ \\ ${ }^{1}$ Facultad de Ciencias Sociales y Económicas, Universidad Católica del Maule, Talca, Chile. \\ *E-mail de contato: fmdelacuadra@gmail.com
}

Resenha recebida em 18 de outubro de 2016, versão final aceita em 17 de janeiro de 2017.

O livro América Latina: Sociedade e Meio Ambiente, organizado por Dimas Floriani e Antonio Elizalde Hevia, é o resultado de um esforço editorial realizado pela Rede Casla-Cepial, em associação com a Editora da Universidade Federal do Paraná (UFPR), que tem por objetivo difundir para um público não necessariamente acadêmico as recentes reflexões que vêm sendo produzidas sobre diversas problemáticas da região, relacionadas a questões como a construção democrática e da cidadania, os direitos humanos e a tragédia dos migrantes, a crise socioambiental e a mudança climática, a pobreza e as deficiências do sistema agroalimentar.
Embora o título do livro apareça em português, trata-se de uma publicação bilíngue, que recolhe as contribuições de especialistas do Brasil e de outros países de língua hispânica do continente, tais como Argentina, Chile, Colômbia e México. Dividida em três seções bem articuladas, a obra traça uma excelente panorâmica da relação entre sociedade e meio ambiente, quer dizer, da história que se tem edificado entre a humanidade e a natureza da qual somos parte. Nos 11 capítulos, os autores e autoras elaboram uma visão ampla, profunda e crítica sobre as formas hegemônicas de imposição de uma narrativa restrita de poder, de saber e de ser. À luz desse 
contexto, considera-se legítima somente a narrativa provinda do pensamento eurocêntrico, que teve e continua tendo efeitos deletérios evidentes sobre a dimensão ambiental, configurando os cimentos da crise sistêmica que enfrenta a humanidade.

Abordando um amplo e inevitável conjunto de temáticas e problemáticas ambientais, tais como pensamento ambiental latino-americano; teorias do desenvolvimento; colonialidade; epistemologia ambiental; retóricas relacionadas ao conceito de meio ambiente e desenvolvimento sustentável; representações e conflitos socioambientais, entre outros, um eixo transversal dos diversos capítulos poderia se situar em torno de um diagnóstico crítico relativo às consequências de um tipo de desenvolvimento associado à noção de crescimento que forma parte da civilização do capital. Por sua parte, um segundo leque de preocupações abordadas pelos autores se concentra ou converge na procura de respostas e soluções aos problemas previamente diagnosticados. Esse segundo corpo de aportes permite vislumbrar, em primeiro lugar, a potência e originalidade do pensamento ambiental latino-americano, constituindo-se numa inesgotável fonte de propostas e saídas para enfrentar a crise, tanto no nível teórico, epistêmico e ontológico como por meio de mediações e expressões práticas de modalidades alternativas de um Bom Viver.

Num primeiro âmbito, dos trabalhos e reflexões que participaram do Programa de Pesquisa Modernidade/Colonialidade, surgem as bases de uma teoria crítica da formação do discurso eurocêntrico. Nesse discurso, consagra-se um tipo específico de trânsito, que evolui desde o estado de natureza para uma forma de estado ou sociedade civil a partir da qual se legitimam as formas convencionais de um determinado ordenamento jurídico, econômico, político, social, cultural e ideológico, o qual vem se irradiando desde a Europa para o resto da humanidade. Essa "metanarrativa" supõe uma visão universal da ideia de progresso - com as suas consequentes classificações e hierarquizações -, a naturalização de relações sociais desiguais, a ontologização das múltiplas cisões da sociedade europeia (homem-natureza; mente-corpo; pensar-sentir, etc.) e o estabelecimento da superioridade dos conhecimentos dessa sociedade sobre as demais. De acordo com essa perspectiva, a elaboração intelectual do processo de modernidade produziu, quase que naturalmente, um padrão mundial de relações de poder baseadas na sedimentação da superioridade da civilização europeia ocidental como estrutura de dominação global, nas formas de saber e de ser.

Diferentemente dessa ontologia, que funda a racionalidade moderna e configura a lógica da ciência eurocêntrica, constitui-se aquilo que Enrique Leff (2016) denomina de ontologia da diversidade e ética da outridade, que proporciona consistência a uma política da diferença e a um diálogo de saberes. Como bem nos adverte esse autor, o ambientalismo de cunho latino-americano, centralmente presente numa nova racionalidade ambiental como princípio mobilizador para uma verdadeira sustentabilidade, afirma-se numa ontologia do diverso frente a uma ontologia unificadora que se manifesta nos efeitos mais perversos sobre a própria vida. Dessa maneira,

a ontologia da diversidade e da diferença e a ética da outridade se convertem em princípios para uma política e uma ética ambiental [...] gerando uma política de sustentabilidade ecológica, de convivência social e autonomia cultural que se tem plasmado em novos desenhos constitucionais e que inspira e orienta os direitos humanos de nova geração. (Leff, 2016, p. 27).

Pelos mesmos motivos, a crise ambiental que ameaça o planeta evidencia os limites da racionalidade econômica e instrumental predominantes no conhecimento moderno, uma racionalidade que 
se expressa fundamentalmente por meio de um modelo econômico e socialmente hegemônico que reduz o desenvolvimento ao crescimento. Então, constata-se que a problemática ambiental não reside exclusivamente no impacto que se apresenta em determinados ecossistemas (contaminação do ar, água, solo, desmatamento, perda de biodiversidade, aquecimento global etc.), mas é resultado de um processo civilizatório construído sobre o conhecimento científico, valendo-se de uma racionalidade formal, instrumental e econômica que permeia uma forma de entender o mundo para poder dominá-lo, explorá-lo e mantê-lo sob controle, com esteio nos interesses das grandes corporações. Contrariamente, na região, está-se gestando uma resistência crítica a esse modelo simulador de sustentabilidade, forjando-se novas visões e estratégias de relacionamento e convivência com a natureza.

Uma dimensão que surge como transversal a vários capítulos incluídos nesta coletânea é a percepção compartilhada de que, apesar dos veementes esforços teóricos e práticos por gerar alternativas a um tipo de desenvolvimento predatório, as recentes medições de um vasto agregado de indicadores continuam evidenciando que a tendência para a degradação ambiental, na maioria dos países, não parou de se agravar. Isso implica precisamente que a distância entre o discurso e a práxis concreta mantém a incógnita a respeito da relação entre desenvolvimento e sustentabilidade - dois conceitos, aliás, consideravelmente polissêmicos -, existindo uma enorme diversidade de perspectivas defendidas por uma multiplicidade de correntes e atores.

O estudo realizado por Enrique Aliste e Violeta Rabi, exposto no capítulo "Representações e representatividade dos discursos do desenvolvimento: Um olhar socioambiental", deixa claramente estabelecido que as diversas visões sobre desenvolvimento e sustentabilidade existentes entre empresários e fazedores de políticas públicas, por um lado, e movimentos sociais e organizações cidadãs, por outro, não possuem convergências, sendo que, para os primeiros, o fator ambiental é parte significativa do discurso econômico como atributo ou valor crematístico que se negocia no mercado como um bem intangível e como uma economização do natural. Contrariamente, para os representantes da sociedade civil que integram organizações de base, as temáticas ambientais se inscrevem num marco de desenvolvimento inclusivo, em que eles desejam ser consultados sobre o tipo de desenvolvimento ao qual aspiram. Dessa forma, a inclusão do sustentável na formulação de políticas públicas ambientais emerge mais como um assunto discursivo que como uma proposta programática a ser executada pela integralidade dos atores envolvidos nos processos de desenvolvimento.

As discrepâncias discursivas e as diversas interpretações sobre a sustentabilidade também são abordadas no capítulo do sociólogo Dimas Floriani, "As retóricas da sustentabilidade na América Latina: Conflitos semânticos e políticos no contexto de Modernidades múltiplas”. Em sua pesquisa, o professor Floriani analisa os diferentes campos discursivos nos quais se apoiam as narrativas provenientes de comunidades epistêmicas que se situam, por uma parte, desde um locus teórico do centro (epistemologias logocêntricas) a outras que se instalam em espaços mais amplos e diversos a partir de epistemologias da multiplicidade cultural ou de diálogo intercultural (epistemologias culturais). Ambos os discursos, que se situam em trincheiras semânticas opostas, intentam transmitir certa coerência entre teoria e prática, ao mesmo tempo em que se autoinstituem representantes legítimos de uma noção de sustentabilidade mais institucional e hegemônica em conflito com a retórica daqueles atores não integrados que contestam dita hermenêu- 
tica oficial como válida e universal para a totalidade dos habitantes do planeta.

A emergência de conflitos socioambientais como consequência de diversas miradas e práticas espaciais sobre determinado território é a reflexão que empreendem Rosinere Martins Lima e Joaquim Shiraishi no capítulo intitulado "Conflitos socioambientais: $\mathrm{O}$ direito ambiental como instrumento de legitimação das ações do poder público. Intervenção no Jardim Icaraí, Curitiba". Em seu texto, os autores destacam que, nesse caso concreto, a existência dessa modalidade de conflito observada num bairro da cidade de Curitiba é o resultado da contradição entre os discursos e usos oficiais dos agentes governamentais de um lado e, do outro, das formas concretas de apropriação do espaço desde as comunidades que nele habitam. Para os primeiros, é preciso fazer uma realocação dos habitantes, nos termos da legislação que define uma zona como Área de Proteção Ambiental (APA), uma vez que por ela percorrem o rio Iguaçu e suas várzeas. Diferentemente, para os moradores, a forma de assentamento utilizada pelas famílias não representa nenhum risco para a preservação do rio. A partir da crítica a um pretenso "objetivismo" que coloca o conflito ambiental como um enfrentamento em torno do uso e apropriação dos recursos, os autores centram sua análise nos diversos significados que o meio ambiente possui para indivíduos e comunidades. Como resultado desse confronto, a dimensão ambiental se configura a partir de seu conteúdo simbólico, quer dizer, tais conflitos surgem como "produtos de uma forma de se pensar e ordenar a cidade, portanto não somente expressam as contradições, como também manifestam os embates pela apropriação e uso dos lugares na cidade". (Lima \& Shiraishi, 2016, p. 258).

Desde uma perspectiva da solução esboçada em vários capítulos, alguns autores vão construindo alternativas com maior ou menor viabilidade para sair desse impasse desenvolvimentista em sua versão convencional, apelando certamente a uma boa dose de otimismo, necessário para pensar horizontes de uma racionalidade ambiental que supere os efeitos perniciosos do atual padrão de produção e consumo. Destacamos, entre elas, a proposição de Gerardo Milioli e Izes de Oliveira, consistente no esforço de transformar o metabolismo linear das cidades em outra forma de metabolismo circular que permita reconverter o desmedido consumo e produção de lixo das grandes urbes por meio de uma redução e reutilização dos resíduos e dejetos, sob uma perspectiva ecossistêmica de uso sustentável dos recursos. Partindo-se desse olhar ecossistêmico, os autores advertem sobre a interconexão entre os problemas urbanos e socioambientais, entre os quais a impermeabilização do solo e o uso desproporcional de combustíveis fósseis ocupam um lugar destacado na deterioração da qualidade de vida das urbes. Para transformar o metabolismo linear das cidades em outro de tipo circular, eles sugerem nove estratégias, que implicam uma conscientização daqueles que habitam nas cidades e que aspiram a uma vida mais digna. Tal conscientização estaria materializada em uma atitude coletiva orientada à mudança, com mentalidade positiva e inovadora. Nesse sentido, a proposta da cidade como um ecossistema sustentável, longe de significar uma metáfora ou um horizonte utópico, representa "uma visão de futuro para crescer com qualidade, diversificar possibilidades e desenhar os limites da natureza". Isso concretamente supõe ter "mais árvores, mais bicicletas e menos tráfego, mais espaços públicos e lugares de encontro e mais encontros, atenção com o outro, à água, ao ar e ao solo e respeito aos recursos". (Milioli \& Oliveira, 2016, p. 133).

Em seu ensaio sobre as capacidades humanas, A Arte de Amar, Erich Fromm advertia-nos há exa- 
tamente seis décadas que um elemento central da crise existencial do homem moderno era a ruptura da simbiose entre homem e natureza. Certamente, Fromm pensara no homem ocidental, pois dita cisão dificilmente se daria nas comunidades que, até mesmo na atualidade, mantêm uma relação harmônica com a natureza. Para Fromm, pensar no homem ocidental representava uma verdade universal indiscutível, pois toda sua reflexão, com fundamento em uma perspectiva psicanalítica renovada, tinha como marco de referência a humanidade ocidental.

A partir de um enfoque diferente, o pensamento ambiental latino-americano se nutre de outra experiência e de outra filosofia, aquela que se encontra enraizada em outros saberes vernáculos próprios dos povos originários de nosso continente. Essa cosmovisão, construída no decurso de muitos anos pelas comunidades que residem na região andina e em outros territórios do continente, concebe o ser humano como parte de um todo integrado, em harmonia com a natureza e com o resto dos seres vivos que habitam no mesmo espaço-tempo. É pensar a vida como uma vasta teia de relações, na complexidade ecossistêmica e nas suas relações sociais, relevando a alteridade como elemento fundamental de construção do ser. É o reconhecimento de que existem diversos valores e formas de entender o mundo, de respeito a todos os seres vivos que integram e convivem na nossa Casa Comum.

Dessa maneira, segue-se como indispensável conjugar o verbo ecologizar - no sentido que lhe imprime Bruno Latour - como construção de uma política na qual a natureza não se separa da huma- nidade e em que não existe uma emancipação dos limites da natureza. Ecologizar supõe uma prática necessária de convivência com o entorno, de profundo respeito com o meio ambiente e que supera a concepção de um desenvolvimento convencional que coloca ênfase na manutenção das utilidades no transcorrer do tempo, uma orientação econômica de matriz antropocêntrica, baseada numa lógica evolucionista e positivista da ciência, que associa, em definitivo, o desenvolvimento com a ideia de progresso e crescimento ilimitado. Frente a essa perspectiva, a contribuição do ambientalismo se apresenta como prática e filosofia de vida, como um modo de entender o mundo e como uma alternativa factível de soluções pensadas num horizonte de médio e longo prazo.

Nessa senda, esse livro, de recente lançamento, vem confirmar o argumento de que o pensamento crítico latino-americano se encontra numa etapa de renovada efervescência e não de crise ou decadência, como afirmam alguns profetas do conservadorismo. Em suas páginas, encontraremos um conglomerado de chaves e miragens para vislumbrar algumas saídas à crise que atualmente enfrentamos e, nessa medida, superar os proeminentes obstáculos que existem para um autêntico desenvolvimento regional e mundial. Pensamos sinceramente que a presente publicação poderá vir a se constituir num relevante avanço e num referencial para todos aqueles que desejam colher subsídios para uma reflexão sobre novos caminhos teóricos e futuras práticas na direção de uma vida mais digna e plena para a imensa maioria dos habitantes da Nave Terra. 